\title{
ballot
}

\section{Integridade eleitoral: significado e critérios de qualificação}

Frederico Franco Alvim ${ }^{\mathbf{1}}$ (UFGoiás, Brasil)

fredericoalvim@yahoo.com.br

Av Historiador Rubens de Mendonça, 4750

Bosque Saúde Cuiabá, MT, 78050-000

1. Analista Judiciário do TRE-SP. Doutorando em Direito (UMSA). Pós-graduado em Direito e Processo Eleitoral (UFG). Especialista em Direito Eleitoral (UNAM). Autor da obra: "Curso de Direito Eleitoral" (Editora Juruá, 2014). Professor de Direito Eleitoral. 


\title{
Resumo
}

O artigo procura apresentar uma definição ampla e prescritiva do âmbito da democracia. $\mathrm{O}$ processo eleitoral, amplamente considerado como um dos pilares dos regimes democráticos, é na verdade, apenas um ingrediente mínimo para a democracia. $\mathrm{O}$ conceito democrático em toda a sua amplitude é baseado na garantia dos direitos que permitem aos cidadãos votarem livres de obstáculos sociais e econômicos.

Palavras-chave: Democracia; direitos fundamentais; processo eleitoral

\begin{abstract}
The article seeks to present a broad and prescriptive definition of the scope of democracy. The electoral process, widely considered one of the pillars of democratic systems, is in truth only a minimum ingredient for democracy. The democratic concept in all its breadth is based on the guarantee of rights that allow citizens to vote free from social and economic hindrances.
\end{abstract}

Keywords: Democracy; fundamental rights; electoral process 


\section{Introdução: o papel das eleições no sistema político}

A essência do regime democrático transcende a ideia de processo eleitoral: para a democracia, as eleições constituem uma condição necessária, porém não suficiente (Sartori 2009: 108). Seu verdadeiro alcance alia a garantia de participação na formação do poder a um estádio de atuação governamental identificado pela construção de uma sociedade em que se compartam os demais direitos fundamentais. A democracia é assim um sistema de expectativas (Fayt 2009: 4), caracterizado não apenas pelo aspecto representativo, mas também pela busca do amplo desenvolvimento social. Nesse caminho, Bobbio (1959: 38) nota que, ao falar-se de democracia, é comum que não se refira a certas instituições ou procedimentos, mas a um ideal perseguido, ao fim que a partir daqueles procedimentos procura-se alcançar. Mais do que pelas ferramentas de que se vale, o regime democrático é caracterizado pelos valores fundamentais que o inspiram e aos quais tende. ${ }^{2}$

Não se desabona, com isso, o processo eleitoral. Pelo contrário, embora se fale também em democracia econômica (com uma universal e verdadeira satisfação das necessidades básicas) e democracia social (com a democratização de todos os espaços coletivos, e não apenas do Estado), a democracia política é condição indispensável para a conquista das outras duas (Salas 2006: 26). Isso porque, como aponta Canotilho (2003: 292), em Estados regidos pelo princípio da soberania popular a dominação política não é um pressuposto naturalmente aceito; ao revés, exige uma justificação original, proporcionada justamente pela eleições, traduzidas em um procedimento pelo qual os membros da comunidade elegem representantes que exercerão o seu governo. As eleições têm como objetivo, portanto, produzir um poder temporal amplamente admitido, a partir da extração da vontade do povo. ${ }^{3}$

O processo eletivo, porém, tem substância neutra. Se a democracia exige mais do que a realização de eleiçóes, estas podem existir sem que haja democracia. Mesmo regimes autoritários realizam consultas populares; isso lhes confere uma aparência de democracia. Nesse contexto, a depender dos graus de liberdade, abertura, legalidade e lisura assumidos, as eleições tanto podem servir para dar origem a democracias genuínas como podem fortalecer regimes alheios às aspirações populares. $\mathrm{O}$ fenômeno pode ser explicado a partir das funções atribuídas às eleições.

Segundo Pinto, Correia e Seara (2009: 358-360), no cenário político são quatro as funções desempenhadas pelo procedimento eleitoral: proporcionar governo; oferecer legiti-

2. Trata-se de uma visão associativa a respeito das faces procedimental e material da democracia. Conforme Vânia Aieta (2006: 55), o perfazimento do princípio democrático em um Estado de Direito ocorre com a junção de ambas as dimensões: a dimensão procedimental, que vincula a legitimação do Poder ao atendimento de determinadas regras e processos (entre os quais cobra destaque a realização de eleiçóes); e a dimensão material, identificada pela observância de valores e princípios, tais como a soberania popular, a garantia dos direitos fundamentais, o pluralismo político e a organização política democrática.

3. Farias Neto (2011: 181) discorre sobre o prestígio conferido ao método eleitoral, diante de outras formas de assunção do poder: "Embora os atos de força possam alçar ao poder, eventualmente, pessoas preparadas, a escolha de governantes mediante revolução e golpe de Estado devem ocorrer apenas de forma acidental. Caso contrário, a coletividade estatal decairia em anarquia e o governo ficaria usurpável por aventureiros e conspiradores oportunistas, tornando o poder não instrumento de ordem, mas de desordem permanente. Por conseguinte, a eleição consiste no critério mais aceitável para a escolha de governantes em razão de apresentar menos inconvenientes, constituindo, assim, uma condição essencial de liberdade que fica expressa no âmbito da coletividade. Ainda que seja imperfeito, a eleição é o critério que assoma mais aderente aos interesses públicos do Estado, além de ser mais flexível e mais suscetível a aperfeiçoamentos contínuos [...]”. 
mação; produzir representação; e gerar participação política. O primeiro aspecto liga-se ao fato de que as eleições permitem que um grupo (partido ou aliança partidária) defensor de uma determinada opinião política passe a ocupar a direção do poder executivo. A respeito da legitimação, decorre da certeza de que, nos regimes democráticos, a vontade política manifestada pela via eleitoral é a única via legitimadora do poder político. Quanto à produção de representação, corresponde à ideia de que somente o mecanismo eletivo logra resolver de maneira adequada $\mathrm{o}$ problema da titularidade do poder, que pertence ao povo, e deve ser exercido em nome daquele. Acerca da participação, a disputa eleitoral é o momento destinado para que o corpo de eleitores expresse a sua preferência, a respeito de candidatos e projetos políticos postos à prova. A participação influi de modo incisivo na agenda política, haja vista que os eleitores sempre podem introduzir questóes no debate, sendo certo também que o resultado eleitoral tem - ainda que apenas potencialmente - o condão de pressionar os decisores políticos, no sentido do encaminhamento do projeto majoritariamente selecionado. ${ }^{4}$ Nesse ponto, coincidem com Fayt (2009: 225), para quem as eleições modernas são algo mais do que mera técnica de designação, operando como instrumento de enlace entre a opinião dos eleitores e a futura ação dos representantes, que nesse sentido passam a representar ou incorporar a vontade popular.

Em proposta semelhante, Pedicone de Valls (2001: 91-93) atribui aos pleitos as seguintes funções: garantir jurídica e procedimentalmente a representação política; produzir governos; lograr a participação de maiorias e minorias; limitar o poder no tempo; e legitimar o governo resultante da consulta popular. A garantia da representação deriva da certeza de que a democracia só é possível graças à votação popular. A produção de governo, em sua proposta, realiza-se porque é mediante o processo eletivo que os cidadãos estabelecem $\mathrm{e}$ trocam governos, conforme apoiem ou rejeitem os programas apresentados durante a campanha. A promoção da participação é destacada a partir da constatação de que a democracia representativa não consiste apenas em que o governo seja representativo, mas também de que o seja a própria oposição, visto que nesses regimes não se desginam apenas governos, mas também se elegem parlamentos compostos de maiorias e minorias. A limitação temporal do poder não é senão um aspecto do princípio republicano, que cobra importância na

4. Obviamente, no plano eleitoral a realização da representação política encontra apenas o seu início, traduzido na transferência de autoridade para o desempenho das funções inerentes ao poder. A plataforma democrática, no entanto, vai além dessa feição delegatória, desdobrando-se no exercício de vigilância sobre a atuação dos mandatários. Nesse diapasão, Canotilho (2003: 293-294) oferece uma análise bipartida do conteúdo da representação: o princípio da representação democrática compõe-se de uma feição de forma (representação democrática formal) e outra de substância (representação democrática material). No primeiro caso, a representação significa a autorização dada pelo povo a um determinado órgão, para que autonomamente aja em seu nome. No segundo caso, porém, é que o regime popular encontra acabamento: "A representação democrática, constitucionalmente conformada, não se reduz, porém, a uma simples 'delegação da vontade do povo'. A força (legitimidade e legitimação) do órgão representativo assenta também no conteúdo de seus atos, pois só quando os cidadãos (povo), para além das suas diferenças e concepções políticas, se podem reencontrar nos actos dos representantes, é possível afirmar a existência e a realização de uma representação democrática material" (CANOTILHO 2003: 294). Conclui assim que a representação democrática comporta um momento referencial substantivo, que reconduz a três diferentes ideias: representação como cuidado para com o interesse dos cidadãos; representação como disposição para responder aos desejos e necessidades dos representados; e representação como processo dialético entre governantes e governados, no sentido de uma realização dos interesses universalizáveis da sociedade. 
função de legitimação do Estado..$^{5} \mathrm{O}$ efeito de legitimação, por fim, é amparado pela força extraída da manifestação popular.

Já para Andrade Sánchez (2012: 193-195), nos Estados contemporâneos cabe às eleições o cumprimento destas missões: geração de representação; produção de governo; transmissão pacífica do poder; satisfação da necessidade ritual de participação coletiva; e aferição das reações dos governados. A produção de representação outorgada pelos mecanismos eleitorais ocorre não apenas no plano teórico: recai também sobre demandas concretas, pois que a seleção de candidatos possibilita que adentrem as assembleias legislativas dirigentes de diversas correntes e grupos representativos de interesses gremiais, corporativos e regionais, o que permite que as mais variadas agrupações encontrem canais de expressão dentro do Estado. Quanto à criação de governo, a eleição constitui, para Sánchez, precisamente a base formal sobre a qual se assenta toda a atividade de designação dos atores governamentais. Sobre a legitimidade, o autor (2012: 194) identifica ligação com a noção de sufrágio universal, já que o fato de que praticamente todos os cidadãos (ainda que não o façam) podem participar da função eleitoral é que permite que os dirigentes reclamem para si um título legítimo para sua atuação. Isso porque, ao eliminar a fórmula hereditária para a transmissão de mando, a ideologia liberal estabeleceu na eleição a validade da função governativa. Indo além, chama a atenção para o papel do fenômeno eleitoral na transmissão pacífica do controle do Estado, consignando que as eleições aceitas como forma de renovação dos quadros dirigentes impóem a seus membros a necessidade de se conformarem com os seus resultados, substituindo desse modo a luta violenta pelo poder pelo plano das campanhas em busca de votos. Através das eleições é que se elimina (em circunstâncias normais) o recurso à força, garantindo-se a sucessão de governos sem altercações da paz pública. Sobre as reações dos governados (2012: 195), concebe os pleitos como termômetros efetivos para o desvelo do grau de aceitação ou rechaço das políticas governamentais, de maneira que deles se colhe uma retroalimentação do sistema politico, que permite sejam canceladas, reorientadas ou ratificadas algumas ações do governo. Finalmente, o cientista mexicano remonta ainda a estudos sociológicos que demonstram que as eleições satisfazem uma necessidade ritual de participação coletiva, na medida em que possibilitam a reafirmação de sentimentos de pertença à comunidade nacional.

O oferecimento de governo é resultado alcançado por qualquer espécie de processo eleitoral, seja ele autêntico ou não (a realização de pleitos com exclusão de camadas populares ou com baixo nível de competitividade é uma realidade histórica no cenário nacional). Também assim, qualquer certame eleitoral demonstra-se capaz de, em alguma medida, produzir legitimidade. Por tal motivo, não é raro que regimes despóticos optem por realizar eleições, atentos ao valor simbólico que sua celebração carrega; ainda que simulados, os pleitos oferecem às máquinas de propaganda um inegável discurso legitimador: sempre se pode, quer aos governados, quer à comunidade internacional, dizer - embora sem razão - que o regime é sustentado pelo povo. Sem embargo, somente eleiçóes realizadas em marcos de abertura e

5. Tal como posto por Dahl (2001: 109), além de justas e livres, a democracia necessita de consultas frequentes, pois sem essas os cidadãos perderiam o controle sobre o resultado do trabalho dos representantes eleitos. 
legalidade apresentam-se aptas a gerar uma legitimidade popular, capaz de conferir ao governo emergente uma estável e pacífica aceitação. ${ }^{6}$ Somente em contornos democráticos ganha o povo o governo de si, a partir do quê se pode falar em uma genuína representação popular. Nessa vertente, Pipa Norris (edição kindle 2014: 193) argumenta:

Ideally, [only] when elections work well, they can select officeholders and governments, determine policy priorities, link citizens (as principals) with representatives (as agents), generate inclusive legislatures, confer legitimacy on elected authorities, hold leaders to account, and provide the main opportunity for most ordinary people to participate in politics.

Em conclusão, embora eleições autoritárias também produzam governo e, com muitas ressalvas, alguma legitimidade, apenas as eleições íntegras realizam, em todos os seus sentidos, todas as suas funções. Nesses regimes, os processos eleitorais: franqueiam ao povo a participação política, pela concessão do direito e respeito ao sentido do sufrágio; produzem representação, mediante a escolha de cidadãos que agirão a serviço do povo; proporcionam à sociedade um governo, assumido pelo grupo representativo das opinióes políticas que se verificaram de preferência majoritária; e legitimam o poder político pela via do consenso, conferindo aos mandatários autoridade suficiente para o desempenho de suas funções. ${ }^{7}$

\section{A integridade das eleições}

O conceito de integridade cinge-se à necessidade de custódia da franqueza da disputa eleitoral, sem a qual se veria frustrado seu mote instrumental de legitimação. Como reporta Renato Janine (2001: 59), o ponto forte da democracia é que, quando os assuntos públicos se resolvem pelo voto, a aceitação dos derrotados é maior do que em outros procedimentos de solução. Por isso, em sua opinião:

[...] é tão importante que uma eleição seja livre e honesta. Ninguém fica feliz de perder. Mas, se noto que o jogo foi limpo, aceito melhor o resultado do que se tenho que engo-

6. Edurne Uriarte (2002:53) explica que a legitimidade corresponde à aceitação do poder político e dos governantes por parte dos governados. Nesse contexto, os governados obedecem porque acreditam que devem obedecer, e isso ocorre porque a relação de autoridade estabelecida é tomada como justa. O fenômeno da legitimidade, assim, tem como efeito produzir uma obediência mais consistente e estável, já que a coação física e o uso da força não bastam para gerar uma ordem política (Vilas 2013: 13). No caso particular da legitimidade democrática, baseia-se, conforme Uriarte (2002: 54), sobretudo na crença da superioridade desse sistema político sobre outros ensaiados ao largo da história, e no cumprimento dos nobres valores encampados pela democracia (liberdade, igualdade, justiça, etc.).

7. A respeito do consenso, veja-se a assertiva de Valls (2001: 51): “Definimos el consenso como la actitud de un conjunto de personas que se traduce en la aceptación o el comportamiento convergente y articulado con respecto a un fenómeno específico. En los regímenes democráticos tiene particular significación, ya que reviste de legitimidad a sus instituciones al posibilitar la aceptación común de las leyes, las reglas y las normas que aquéllas promulgan, dando cuerpo y sustento a un sistema de creencias compartido. El consenso permite prever la conducta de una sociedade, y, además, elimina y evita conflitos. Su misión fundamental es sostener el orden público". Como en la sociedad no puede haber consenso universal, el consenso parcial preponderante es el que da legitimidad a las instituciones y facilita el equilibrio propio de los regímenes democráticos". 
lir, além do resultado, também a sensação de que houve fraude.

[...] O essencial dessa posição é que a democracia é um jogo. Eticamente, não é um jogo superior nem inferior a outros. Mas é mais eficaz na aceitação da derrota. Por isso, produz relaçóes sociais melhores, mais pacíficas, de melhor cooperação.

De fato, se as eleições existem para que se promova, de maneira pacífica, a periódica transmissão do Poder, somente quando íntegras cumprirão o seu papel institucional. Se o ato eleitoral não se desenvolve de acordo com normas rígidas dirigidas a assegurar a pureza $\mathrm{e}$ a verdade da vontade política que nele se expressa, a eleição não tem razão de ser e, portanto, nada significa (Gros Espiell apud Freitas 2009: 95). Um processo eleitoral manipulado não cumpre em sua essência a função legitimadora do poder ${ }^{8}$; qualquer democracia que dele se extraia não será mais do que uma ficção política. Nessa senda, Gomes (2010:49) defende não haver dúvida de que, nos tempos atuais, sociedades verdadeiramente democráticas exigem que as escolhas dos governantes realize-se por meio de processos pautados por disputadas limpas, isentas de vícios, corrupção ou fraude.

Para além da esfera da legitimação, a integridade atua ainda como elemento de qualificação do regime popular, na medida em que o vigor global do sistema democrático depende do grau de observância e respeito da temática eleitoral (Nohlen e Sabsay 1997: 18). Nas democracias, o poder não pode se basear senão no consentimento dos governados, de maneira que a autoridade consensual extraída das eleições aparece como cerne da aceitação política (Valls 2001: 60).

A integridade eleitoral é garantida a partir da observância de uma série de mandamentos? No presente trabalho, condensam-se as exigências em cinco critérios considerados principais: a garantia de liberdade para o exercício do sufrágio; a estrita observância da legalidade da disputa; o reconhecimento da autenticidade de seus resultados; a certeza de imparcialidade e firmeza na condução das eleiçóes pelos órgãos de administração e jurisdição eleitoral; e a preservação da igualdade de oportunidade entre os candidatos que se submetem à escolha popular.

\subsection{A garantia de liberdade para o exercício do sufrágio}

A liberdade para o exercício do sufrágio prescinde de dispositivos expressos para que seja extraída do texto constitucional: cuida-se de exigência inerente ao espírito democrático por

8. Pelo contrário, eleições manipuladas geram uma série de graves problemas. Na visão de Pippa Norris (edição kindle 2014: 194), entre outras consequências, podem induzir à diminuição da confiança nas autoridades eleitorais, ao aumento da abstenção eleitoral, à exacerbação de conflitos e à mudança das regras, não necessariamente para melhor.

9. Em visão mais ampla, Alejandro Tullio (2010:18-19) defende que no caminho para o reconhecimento da integridade eleitoral, deve-se consentir que os marcos legal, político e social assegurem que: a autoridade eleitoral seja imparcial e totalmente independente, e que no desempenho de suas funções jurisdicionais cuide para que se cumpra a normativa eleitoral; que a legislação preveja a existência de mecanismos processuais manejáveis diante de qualquer atividade que restrinja arbitrariamente direitos políticos; o sufrágio igual e universal esteja efetivamente reconhecido; o direito ao voto secreto seja facilitado pelos mecanismos escolhidos; o resultado eleitoral reflita exatamente a preferência dos votantes; os cidadãos estejam registrados sobre a base de seus respectivos domicílios eleitorais; exista ampla liberdade para organização política e postulação de cargos eletivos, salvo restrições legais estabelecidas de maneira razoável e prévia ao processo eleitoral; os candidatos vejam assegurado o direito a competir em um marco de segurança e confiabilidade tanto pessoal como institucional, onde as liberdades de expressão, difusão de ideias pela imprensa livre, associação, petição e reunião sejam estritamente respeitados; e a ocupação dos principais cargos institucionais do país seja fruto de eleições livres, confiáveis e transparentes. 
ele conformado. No caso brasileiro as normas que prescrevem o voto secreto e a exigência de eleições normais e legítimas (arts. 14, caput e $\$ 9^{\circ}$, da Constituição Federal) estão, implicitamente, conclamando a inafastabilidade do voto liberto.

A respeito da liberdade, Reis (2012:78) assinala que o direito de votar não é meramente processual, isto é, não se perfaz em admitir a emissão de uma determinada opinião eleitoral. Mais do que isso, constitui uma grandeza jurídica substancial. A expressão da vontade contida nesse ato, portanto, deve ser a consequência da aplicação de uma série de garantias destinadas a “[...] permitir que a opção eleitoral seja alcançada de forma livre de coações morais ou materiais e que seu exercício se dê sem a intercorrência de quaisquer modalidades de fraude". Em inclinação semelhante, Sánchez Muñoz (2007: 37) adverte:

La elección se expresa a través del voto, pero el voto en sí puede no ser la expresión de una auténtica elección. En una democracia, el derecho de sufragio no consiste solo en un derecho a votar, sino también, como presupuesto prévio, en un derecho a elegir y hacerlo en libertad. En otras palavras, para que el sufragio pueda ser considerado como democrático no basta con que todos los ciudadanos tengan la facultad de introducir una papeleta con el nombre de unos candidatos en la urna, es necesario que puedan realmente elegir, es decir, que puedan escoger libremente entre distintas alternativas políticas. Eso es lo que nos permite diferenciar unas elecciones democráticas de unas elecciones meramente aparentes como las que suelen organizarse en los regímenes dictatoriales.

No particular, deve a liberdade ser interpretada da maneira mais ampla possível: a ideia de voto livre desenvolve-se em um duplo pressuposto: em primeiro lugar, que a ninguém é dado interferir na liberdade de escolha do eleitor; mas, mais do que isso, que a liberdade não compreende apenas o momento de realização do voto, senão igualmente as etapas que o precedem, como o registro de candidatos em número suficiente para que o eleitor disponha de alguma alternativa (Mendes, Coelho e Branco 2008: 734-735).

O mesmo raciocínio pode ser aplicado à fase da campanha, já que o espírito de liberdade atrela-se, necessariamente, à exigência de que a vontade sufragante seja sumamente protegida, para que surja de modo espontâneo, isento da influência viciante de todas as formas de abuso de poder. ${ }^{10}$ A liberdade para o exercício do voto encontra ainda na etapa de campanha outra importante face, relacionada com a composição de um ambiente isonômico entre aqueles que disputam a opção do eleitor. Afinal, para que haja liberdade é igualmente necessário que os sujeitos que os postulantes tenham obtido uma oportunidade substancialmente igual de - por meios obviamente legítimos - influir na decisão dos votantes. Para Sánchez Muñoz (2007: 38), sem a garantia dessa igualdade os eleitores sujeitam-se a concluir a partir verdades parciais ou informações manipuladas, o que evidentemente representa um menoscabo do seu direito de escolher em liberdade.

A liberdade para o exercício do sufrágio depende ainda da garantia de sigilo, precaução indispensável para a regularidade dos pleitos, na medida em que opera uma significativa re-

10. Nesse caminho, Salgado (2010:35) propóe que a integridade da disputa eleitoral, entre outras coisas, deve ser garantida a partir da a proteção contra determinadas condutas, em defesa dos direitos subjetivos de cada eleitor. 
dução da pressão que se exerce sobre o eleitor e atua como elemento inibidor de expedientes como a compra de votos, haja vista que gera para o corruptor um risco identificado pela ausência da contrapartida no ato de negociação do voto (Speck 2003: 157).

\subsection{A preservação da legalidade da disputa}

Entende-se por lícito o pleito marcado pelo respeito às regras do jogo, independentemente do conteúdo que arrastem consigo. Por esse raciocínio, processos eleitorais promovidos em sistemas de democracia limitada podem, tecnicamente, ser considerados legais. Dificilmente, porém, seriam reconhecidos como íntegros pela comunidade internacional.

Conquanto etimológica e logicamente associados, os conceitos de legalidade e legitimidade não se confundem. Pinto, Correia e Seara (2009: 150) destacam que ambas as noçóes situam-se em campos científicos autónomos, o primeiro na teoria do direito, o segundo na filosofia e na ciência políticas. Para os autores, a ideia de legalidade remete a aspectos de conformidade com o ordenamento, de maneira que seu problema pode ser resolvido a partir da análise de dois aspectos centrais: a produção do direito através das leis e a aplicação do direito de acordo com as leis. Noutra volta, consignam que, ao passo em que a legalidade opera no plano normativo, a legitimidade atine ao plano axiológico ${ }^{11}$, de modo que sua lógica aferitiva atrela-se à afirmação do caráter justo de certa ordem, poder ou - caso das eleições - processo. As notas distintivas entre legalidade e legitimidade são também delineadas por Bonavides (2014: 120-121): ao passo que a legalidade exprime a ideia básica de observância das leis, isto é, de adequação procedimental para com o direito estabelecido, a legitimidade tem "exigências mais delicadas", pois levanta um problema de fundo, relacionado com a justificação e com os valores do que é legal, de maneira que "a legitimidade é a legalidade acrescida de valoração".

O problema da integridade necessita, portanto, de uma avaliação presa não apenas a qualquer legalidade neutra, mas à constatação de que a licitude que a sustenta seja informada por valores democráticos e republicanos, como a igualdade, a pluralidade e o respeito à liberdade (Lince 2006: 37). Enquanto fundamentos do arquétipo democrático, tais elementos devem compor o ethos do ordenamento eleitoral, cuja missão passará por estimular-lhes e oferecer- lhes constante e consistente guarida; haverão de alimentar sua essência, de compor o seu substrato ético, de inspirar o desenvolvimento de suas normas e também delinear, para os intérpretes, os contornos de sua aplicação.

Fica desse modo claro que a lógica da legalidade somente é admitida como corolário ou pressuposto básico para o reconhecimento da integridade eleitoral. $\mathrm{O}$ profundo significado da técnica eletiva não se realiza apenas com a análise fria da conformidade das práticas verificadas para com o direito positivo, já que eleições íntegras não existirão senão quando realizadas sob a égide de ordenamentos legítimos, segundo o prisma valorativo. Fixa-se assim a exigência de que se busque algo além da estrita observância da lei no processo, já que um juízo de mera correição formal seria incapaz de alimentar, no corpo social, o grau de aceitação necessário à conformação do sistema democrático representativo. A integridade, nesse passo, relaciona-se com o conteúdo do direito eleitoral positivo. Os conceitos de integridade e legalidade das eleiçóes se comple-

11."Mas se a legalidade opera no plano normativo, a legitimidade releva do domínio da Justiça, na medida em que a indagação é aí da compatibilidade com uma dada grelha de valores [...]. Legítimo será, nessa medida, aquilo que é concordante com um determinado sistema de crenças e convicções e como tal encarado pela comunidade de cidadãos" (Pinto; Correia; Seara 2009: 150). 
mentam, atuando em conjunto para cumprir a função de tornar factível a democracia como fonte de sustentação do regime popular.

\section{$2.3 \mathrm{O}$ respeito à autenticidade dos resultados}

Dizem-se autênticas as eleições cujo projeto global traduza, com fidelidade, a vontade externada pelo corpo político. Nesse sentido, o princípio da autenticidade correlaciona-se com a integridade: tem como propósito garantir a geração da energia de legitimidade derivada do respeito à soberania popular na apuração do processo eleitoral. $\mathrm{O}$ preceito, bastante caro para o Direito Eleitoral, é cultuado por Fávila Ribeiro (2006: 4), que dele se vale para conceituar a própria ciência. Em suas palavras, a matéria dedica-se precisamente "[...] ao estudo das normas e procedimentos que organizam e disciplinam o poder de sufrágio popular, de modo a que se estabeleça a precisa equação entre a vontade do povo e a atividade governamental". De todo modo, importa distinguir entre a autenticidade das eleições e a autenticidade de seus resultados. A autenticidade (ou integridade) das eleiçóes pressupóe a autenticidade de seus resultados (Salgado 2010: 33), sem que a recíproca seja verdadeira: a autenticidade dos resultados atua como componente matemático da integridade, motivo pelo qual é aferida de maneira cartesiana, ao final do processo eleitoral. A integridade, em contrapartida, dimana por todo o processo e não se desprende da questão da justiça. Posto de modo mais simples, o princípio da autenticidade do resultado testemunha a inexistência de fraudes no exercício aritmético de colheita e contagem dos votos (número de votos emitidos igual ao número de votos proclamados), ao tempo em que o princípio da integridade atesta a ausência de vícios em todas as fases do evento eletivo, incluindo a etapa de captação da preferência popular (campanha eleitoral).

\subsection{Imparcialidade na condução do processo pelos órgãos de administração e jurisdição eleitoral}

Outro imperativo de autenticidade corresponde à identificação de certeza de imparcialidade e firmeza na condução das eleições pelos órgãos de administração e jurisdição eleitoral. Exige-se que os organismos eleitorais desenvolvam os processos de organização e de verificação da legalidade do pleito com plena observância dos cânones constitucionais. Nesse contexto, assaz importante a realização de um eficaz controle jurisdicional da legalidade no processo eleitoral, tendo em vista que a diminuição de sua incidência tem, cada vez mais, forçado a judicialização das eleições (Pereira 2004: 131). ${ }^{12}$ A assertiva impacta inclusive a preservação da isonomia eleitoral, também encarada como requisito do princípio da integridade. Nessa medida, Roseno de Oliveira (2013: 182) repara que no contexto democrático, em que se destacam aspectos como a concretização da representação e a celebração de eleições habituais como método de legitimação do poder político, "[...] cresce a importância dos organismos eleitorais, ou mais especialmente dos sistemas (modelos constitucionais) de controle das eleições, responsáveis

12. Pereira (2004: 132-133) evidencia a estreita ligação entre a integridade do pleito e a atividade contenciosa realizada pela Justiça Eleitoral, ao destacar que dita atividade tem por objetivo último assegurar a plena eficácia das normas que estabelecem as garantias políticas de cunho eleitoral. Ao registrar que a legitimidade do processo eletivo depende da efetivação das garantias judiciais contra condutas conspurcantes da contenda eletiva, finaliza o raciocínio com a afirmação de que a lisura das eleições só pode ser atingida "[...] através de uma justiça ágil, independente e com credibilidade na opinião pública”. 
por concretizar a interferência estatal para resguardar que as disputas sejam travadas num ambiente de igualdade". Outrossim, o controle das eleiçóes se apresenta como mecanismo fundamental para a proteção do regime das liberdades políticas, à medida que se nota que as liberdades não se implementam puramente no campo normativo, sendo, pelo contrário, em última instância aferidas no mundo dos fatos, onde hão de ser reforçadas por condutas passivas e ativas, entre as quais se destaca a aplicação de sanções por interferências daninhas (Nino 2007: 26).

\subsection{A preservação da igualdade de oportunidades entre os candidatos}

Por derradeiro, um dos aspectos mais importantes a respeito da integridade é identificado pela necessidade da criação de um ambiente de isonomia entre os participantes da disputa. Como sustenta Sánchez Muñoz (2007:4-5), um processo eleitoral desacreditado pela falta de equivalência não tem como cumprir a sua função legitimadora, desencadeando uma corrente de atrofia política em que os governantes deixarão de ser vistos como representantes do povo e em que o sistema político deixará de ser crível. Para o autor (2007: 23), é inegável à saúde da democracia uma modulação que garanta uma suficiente isonomia entre os participantes das contendas eletivas, pois no modelo de democracia competitiva, em que o acesso ao poder depende de uma disputa entre os atores políticos, uma eleição só será autêntica (leia-se: íntegra) se os diferentes postulantes lutem pelos votos dentro de um marco de igualdade de oportunidades. O cumprimento satisfatório desse princípio constitui, nessa medida, um elemento chave para a saúde do sistema.

Manifestando-se sobre o tema, Valls (2001: 35) esclarece que em uma sociedade democrática a igualdade de oportunidades não se refere especificamente à distribuição de distintas posições no estrato social, mas sim em torná-las acessíveis a todos os cidadãos de idêntica maneira, isto é, desde um ponto de partida coincidente em razão do qual seja possível alcançar objetivos dependendo da própria competividade. Em sua visão, para que exista igualdade de oportunidades os indivíduos devem ter satisfeitas as necessidades elementares, o que ocorre quando exista uma equivalência econômica que permita a uniformização das potencialidades, pressuposto da igualdade de acesso. Com o mesmo espírito, Azambuja (1967: 257) preleciona:

A igualdade democrática não é, como alguns aparentam pensar, a negação absurda das desigualdades naturais, que fazem de cada homem um ser diverso de todos os outros. Ela é unicamente a negação das desigualdades artificiais criadas arbitrariamente por injustos privilégios de classes, nascimento e fortuna, que prevaleciam nos regimes aristocráticos.

Sánchez Muñoz (2007: 34) assenta que o respeito à isonomia eleitoral converte-se em um dos elementos básicos do sistema representativo, na medida em que o regime democrático pressupóe um inexorável respeito à ideia de uma ordem política sempre aberta e renovável. Para o especialista, o tema goza de duplo encaixe constitucional, podendo ser vislumbrado tanto pela ótica dos sufragantes como pela ótica dos sufragados. Desde a perspectiva do eleitor, não existe eleição livre sem que exista uma equivalência entre os competidores no momento de influir na formação da vontade eleitoral; pelo prisma do candidato, a competitividade deriva do direito político de acesso a cargos públicos em condições de igualdade. Em raciocínio complementar, Brea Franco (2000: 73-76) ensina que, no contexto das atividades eletivas, para que um processo de escolha possa ser considerado íntegro, não basta que se assegure que 
todo aquele que tenha direito de votar possa fazê-lo em liberdade, igualdade e sem pressóes. Deve-se assegurar, também, que se estabeleça, entre os candidatos, um grau aceitável de competição, o que passa, entre outras coisas, pela garantia de que partidos e candidatos possam ter acesso aos eleitores em um cenário de liberdade e igualdade de oportunidades. Nessa perspectiva, sob a legenda de princípios de regulamentação o autor levanta três condições a serem garantidas pelo Estado no tratamento das campanhas eleitorais: assegurar um regime de liberdades, em especial as políticas (liberdade de expressão, informação e reunião para todos os grupos, partidos e demais participantes do processo eleitoral); manter a neutralidade e imparcialidade dos entes públicos que possam influir no resultado das eleiçóes; e dirigir sua ação com o objetivo de igualar, no que for possível, os meios à disposição dos candidatos, é dizer, promover entre aqueles a igualdade de oportunidades. ${ }^{13}$

Os pressupostos levantados por Franco por certo amoldam-se ao conteúdo do princípio da isonomia entre os postulantes, o qual, para Sánchez Muñoz (2007: 66-69), pode ser bipartido entre a liberdade de acesso à competição (requisito prévio à própria disputa, relacionado com a existência de competidores a ofertar diferentes alternativas políticas), e a igualdade de oportunidades em sentido estrito, ligada à regulação da atuação de sujeitos que intervêm na competição eleitoral (essencialmente os próprios competidores, entretanto sem deixar de lado outros atores capazes de exercer influência, de que são exemplos os veículos de comunicação).

Ainda sobre o tema, Sánchez Muñoz (2007: 71-72) aponta para a existência de duas diferentes dimensões de análise, fincadas, respectivamente, em um viés positivo e outro negativo. A dimensão positiva da isonomia identifica-se com a necessidade do estabelecimento de ações ativas por parte do Estado, no sentido de implementar medidas tendentes à otimização da visibilidade das alternativas políticas através de uma série de prestações estatais, de que são exemplos as medidas relacionadas com a ampliação de espaços publicitários, com o financiamento público ou ainda com o barateamento das campanhas eleitorais. De outra ponta, a igualdade de oportunidades assume também uma dimensão negativa, cujo fim é impedir que situações de superioridade fática sejam aproveitadas de forma exacerbada por parte de alguns competidores eleitorais, o que se materializa mediante ações limitadoras da atuação dos diversos atores políticos.

\section{Conclusão}

Nos regimes democráticos, as eleições correspondem a ferramentas destinadas à conversão da vontade popular em títulos de poder. Prestam-se, nessa medida, à geração de um governo ab origine legítimo, incorporado por mandatários selecionados pela lógica do consenso e, portanto, a princípio respaldados em sua atuação pela aceitação dos governados. Reconhece-se, todavia, que a função legitimadora do evento eletivo não se lhe acompanha de modo automático, decorrendo, mais propriamente, da certificação de um determinado índice de integridade sem o qual a seleção de representantes converte-se em ato simulatório, frágil em efeitos porquanto pobre em substância.

13. Na linha da exigência de nivelamento, Fávila Ribeiro (1988: 64) argumenta não bastar que os diplomas eleitorais consagrem enunciados específicos ao princípio da isonomia jurídica, sendo ainda necessária uma séria atuação no sentido da extirpação de privilégios nas condiçóes concretas das disputas eleitorais. 
O conceito de integridade remete à necessidade de conservação da pureza e da justiça da pugna eletiva, com o mote de preservar a legitimidade e promover a estabilidade do sistema político. Atualmente, a noção de integridade incorpora diversas exigências, destacando-se entre elas o respeito à liberdade para o exercício do sufrágio, a obediência às regras do jogo político, o reconhecimento da autenticidade de seus resultados, a garantia de imparcialidade na condução das eleiçóes e o resguardo da igualdade de oportunidade entre os diferentes candidatos. Da presença desses critérios - ou da confluência desses fatores - é que se apura o sucesso da experiência eletiva, a qualificação que lhe oportuniza estruturar o ponto de Arquimedes do regime popular.

\section{Referências bibliográficas}

AIETA, Vânia Siciliano. Democracia. Tomo II. Coleção Tratado de Direito Político. Rio de Janeiro: Lumen Juris, 2006.

BOBBIO, Norberto. Qual democracia? São Paulo: Loyola, 2010.

BONAVIDES, Paulo. Ciência política. São Paulo: Forense, 2014.

CANOTILHO, J. J. Gomes. Direito constitucional e teoria da constituição. $7^{\mathrm{a}} \mathrm{ed}$. Coimbra: Almedina, 2003.

DAHL, Robert. Sobre a democracia. Brasília: UNB, 2009.

FARIAS NETO, Pedro Sabino. Ciência políticał enfoque integral avançado. São Paulo: Atlas, 2011.

FAYT, Carlos Santiago. Derecho político. Tomo II. 12a ed. Buenos Aires: La Ley, 2009.

FRANCO, Julio Brea. Competencia política y campaña electoral, in: Diccionario electoral. San José: IIDH, 1988, p. 74.

FREITAS, Rubens Correa. Derecho constitucional contemporaneo. $3^{\text {a }}$ ed. Montevideo: FCU, 2009.

LINCE, Rosa María Mirón. El Derecho Electoral como pilar de la transición democrática, in: Derecho electoral. MIGALLÓN, Fernando Serrano (org.). Ciudad de México: Porrúa, 2006, 37-54.

MENDES, Gilmar Ferreira; COELHO, Inocêncio Mártires; BRANCO, Paulo Gustavo Gonet. Curso de direito constitucional. 3a ed. São Paulo: Saraiva, 2008. 
MUÑOZ, Òscar Sánchez. La igualdad de oportunidades en las competiciones electorales. Madrid: CEPC, 2007.

NINO, Carlos Santiago. Introdução à ciência do Direito. São Paulo: Martins Fontes, 2010.

NOHLEN, Dieter; SABSAY, Daniel. Derecho electoral, in: Tratado de Derecho Electoral comparado de América Latina. NOHLEN (org.). Ciudad de México: FCE, 1997.

NORRIS, PIPPA. Why electoral integrity matters. Cambridge: Edição Kindle, 2014.

OLIVEIRA, Marcelo Roseno de. Controle das eleiçóesł virtudes e vícios do modelo constitucional brasileiro. Belo Horizonte: Fórum, 2010.

PEREIRA, Erick Wilson. Controle jurisdicional do abuso de poder no processo eleitoral. São Paulo: LTr, 2004.

PINTO, Ricardo Leite; CORREIA, José de Matos; SEARA, Fernando Roboredo. Ciência política e direito constitucional. Lisboa: Universidade Lusíada, 2009.

REIS, Márlon. Direito Eleitoral brasileiro. Brasília: Alumnus, 2012.

RIBEIRO, Fávila. Abuso de poder no Direito Eleitoral. Rio de Janeiro: Forense, 1988.

RIBEIRO, Renato Janine. A democracia. São Paulo: Publifolha, 2001.

ROUQUIÉ, Alain. El análisis de las elecciones no competitivas: control clientelista y situaciones autoritarias, in: ¿Para qué sirven las elecciones?. HERMET, Guy; ROUQUIÉ, Alain;

LINZ, Juan (orgs.). Ciudad de México: FCE, 1982.

SALAS, Luis Gustavo Arratíbel. Conceptualización del Derecho Electoral, in: Derecho electoral. MIGALLÓN, Fernando Serrano (org.). Ciudad de México: Porrúa, 2006, 1-36.

SALGADO, Eneida Desireé. Princípios constitucionais eleitorais. Belo Horizonte: Fórum, 2010.

SÁNCHEZ, Eduardo Andrade. Introdución a la ciencia política. Ciudad de México: Oxford Press, 2012.

SARTORI, Giovanni. La democracia en treinta lecciones. Ciudad de México: Taurus, 2009.

SPECK, Bruno Wilhelm. "A compra de votos: uma aproximação empírica”, in: Opinião Pública, Campinas, 2003, vol. IX, n. 1, p. 148-169. 
URIARTE, Edurne. Introducción a la ciencia política. Madrid: Tecnos, 2002.

VALLS, María G. Pedicone de. Derecho electoral. Buenos Aires: La Rocca, 2001. 
Recebido em: 15/07/2015

Aceito em: 31/07/2015

\section{Como citar}

ALVIM, Frederico Franco. Integridade eleitoral: significado e critérios de qualificação. Ballot. Rio de Janeiro: UERJ. Volume 1 Número 2 Setembro/ Dezembro 2015. pp. 213-228. Disponível em: [http://www.e-publicacoes. uerj.br/index.php/ballot]

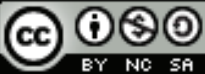

A Revista Ballot está licenciada sob uma licença Creative Commons Atribuição - Não Comercial - Compartilha Igual 3.0 Não Adaptada. 